\title{
Beyond Elementary: Examining Conceptual Demands of Division of Fractions in Current US Curricula
}

\author{
Leanna R. Carollo*, Educational Foundations
}

\begin{abstract}
The Common Core State Standards of Mathematics (CCSSM) is set of U.S. educational standards that were initially adopted in 2010 by 45 states. The CCSSM attempts to create a more rigorous and coherent set of standards for American students, making elementary math anything but elementary. The adoption of these new standards formulates the following research questions for this study: How well do current curricula match the CCSSM and how well do current curricula support teacher knowledge in implementing the standards? Three diverse curricula used in the United States, Prentice Hall, Singapore Math, and CK-12, were examined with three evaluation tools. The tools measure (a) the cognitive demands of the mathematical tasks in each curricula, (b) the mathematical coherency of an instructional unit, and (c) the resources in each curricula that support teachers' understanding of mathematics. The topic chosen for analysis is division of fractions because fractions are frequently encountered in algebra and provide the foundation for higher-level math. This study finds that Singapore Math's problems require higher-level cognitive demands more frequently than Prentice Hall and CK-12. Furthermore, Prentice Hall and CK-12's reliance on the standard division algorithm inhibit conceptual thinking for both students and teachers. Utilizing the Curriculum Review Tool, which focuses on teacher knowledge, I find that Singapore Math is most suitable in meeting the division of fraction requirements set by the CCSSM. To attain demands for the CCSSM, resource tools for teachers can be developed that better support students' learning by combining the strongest characteristics from each curriculum.
\end{abstract}

\section{INTRODUCTION}

\subsection{THE MATH CHALLENGE}

The notion of failing U.S. schools and declining global competitiveness has been and still is the discourse surrounding U.S. education. National projects such as A Nation at Risk, published in 1983, America 200O, published in 1991, and US Education Reform and National Security, 
published in 2012, helped sparked this discourse. A Nation at Risk states that students' SAT scores dropped by 40 points in the mathematic and verbal sections and the need for remedial mathematic courses in colleges increased by 72 percent (Gardner et al., 1983). The US Education Reform and National Security reported that more than 25 percent of students fail to graduate from high school in four years and only 22 percent of U.S. high school students met college readiness standards in all of the core subjects; these figures are even lower for AfricanAmerican and Hispanic students (Klein, Rice, \& Levy, 2012). These projects' findings have resulted in an emphasis on higher test scores and heightened researchers' interest to investigate students' and teachers' knowledge pertaining to math and science. In addition, U.S. students have received only mediocre scores on international tests scores in mathematics (National Center, 2011a; National Center, 2011b). Furthermore, research illustrates that current U.S. mathematical curricula lack focus and coherence, while U.S. teacher knowledge of mathematics is inadequate (Ball, 1990; Ginsburg, Leinwand, Anstrom, \& Pollock, 2005; Ma, 1999). It is debatable to label U.S. schools as failures as well as to emphasize the importance of testing and international rankings. However, the debate has sparked the attention of researchers whose studies have illustrated that there is room for improvement of students' and teachers' knowledge of mathematics in the U.S. This needed improvement is the U.S. challenge in mathematics.

Dr. Alan Ginsburg, formerly with the U.S. Department of Education, and his colleagues compared the United States' and Singapore's mathematic teachers, assessments, standards, and textbooks. The Trends in International Mathematics and Science Study (TIMSS) is an international science and math test conducted every four years for fourth and eighth graders. In the mathematics section Singapore placed first in 1995, 1999, and 2003. In 2007 Singapore's fourth graders placed second behind Hong Kong and its eighth graders placed third (National Center for Education Statistics, 2011a). Ginsburg et al. found that Singapore's mathematical system includes a "highly logical national mathematics framework, mathematically rich problem-based textbooks, challenging mathematics assessments, and highly qualified mathematics teachers whose pedagogy centers on teaching to mastery" (2005, pg. ix). These studies indicate that the U.S. mathematical curricula lack coherency, i.e., a logical progression of ideas, and encouragement of conceptual ideas compared with Singapore's curricula. For my analysis, conceptual understanding is defined as explaining (a) why mathematical procedures are performed and (b) how these procedures can be applied in various situations.

Similar to Ginsburg's et al. study, Dr. Liping Ma, a member of National Mathematics Advisory Panel, compared Chinese and U.S. elementary school teachers' mathematical knowledge. She interviewed 23 above average U.S. teachers with 72 Chinese teachers ranging from satisfactory to above average. Dr. Ma found that although most U.S. teachers have higher degrees than do China's teachers, they have a lesser understanding of elementary mathematics (1999). Deborah Ball, Dean of the School of Education at the University of Michigan, interviewed 252 prospective elementary and secondary mathematics teachers. She found that after their completion of college, prospective teachers' mathematical knowledge was dependent on rules without understanding why they worked (1990). These studies show some U.S. elementary teachers lack a comprehensive understanding of mathematics. Curricula that do not 
support integrated mathematical thinking will make it difficult for teachers to effectively implement the Common Core State Standards (CCSS).

Introduced in 2009, the CCSS was developed in an attempt to enhance mediocre international rankings, inconsistent state standards, and persistent achievement gaps between socioeconomic and ethnic groups. The CCSS attempts to remedy these issues by offering more rigorous standards that states can choose to implement. The CCSS, spearheaded by the National Governors Association for Best Practices (NGA) and the Council of Chief State School Officers (CCSSO), were developed in consultation with teachers, experts, parents, and administrators to create higher standards. Forty-five states have adopted the CCSS, which include English Language Arts (CCSS ELA) and Mathematics (CCSSM), and plan to implement them by 2014.

States that have not adopted the CCSS include Alaska, Texas, Nebraska, Minnesota, and Virginia. These states have not adopted the standards because of their opposition to national tests, skepticism of the standards for improving state education, and fear of losing state control regarding educational standards. The monetary incentive from President Barack Obama's Race to the Top Fund encouraged states to adopt the CCSS. Receipt of educational funding from Race to the Top is dependent on a point scale. States that adopt the CCSS will receive 40 points out of a total 500 points. Some states also accepted the CCSS due to their belief that higher standards and more challenging objectives will improve U.S. education.

Despite opposing views of the CCSS, the standards of the CCSSM stress coherency, focus, clarity, and rigor (National Governors, 2010). Emphasis is placed on conceptual understanding of mathematics rather than memorizing procedures. The standards do not inform teachers how to teach, but rather specify the levels at which students should be performing. Although more resources are currently evolving to help teachers implement the CCSSM, educators will still rely on their manuals as a template to apply the CCSSM because of their familiarity and easy access to the materials. This raises the central research questions: how well do current curricula match the CCSSM and furthermore, how well do the curricula support teachers' mathematical knowledge?

\subsection{SELECTED CURRICULA AND CCSSM TOPIC}

I hypothesize that Singapore Math will most closely align to the CCSSM given that previous research has shown that Asian mathematical programs are generally better developed. To determine how well current curricula match the CCSSM and how supportive they are of teachers' mathematical knowledge, my project will analyze three different curricula materials in relation to the "division of fractions" standard of the CCSSM. These curricula include: Prentice Hall (Charles, 2008), Singapore Math (Singapore Math 2003; 2006), and CK-12 (Greenberg \& Kershaw 2012a; 2012b). For the purpose of my project, curricula are synonymous with the terms "programs" or "teacher manuals."

Curricula have been chosen as one way of examining teacher knowledge because research suggests curriculum materials shape the ideas of a teacher's pedagogical practices and influence 
classroom instruction (Grossman \& Thompson, 2008). It has been shown that teacher knowledge influences student achievement (Coleman, 1966; Hill, Rowan, \& Ball, 2005) and that elementary teachers rely heavily on manuals when teaching (Grossman \& Thompson, 2008). Thus, curricula must be examined to determine how well it supports teachers' mathematical knowledge in achieving the CCSSM. Knowing how well current curricula support teachers' mathematical knowledge will help indicate how prepared teachers are for the CCSSM and potentially how well students will succeed since teacher knowledge influences student achievement.

To answer my research questions, I analyzed three different curricula: (a) Prentice Hall, a long-established published curriculum, (b) Singapore Math, a program based on the math curriculum developed in Singapore, and (c) CK-12, an on-line, open source curriculum.

Prentice Hall Mathematics is the leading publisher of middle school and high school textbooks. In 2008, the U.S. Board of Education approved of its use for mathematic instruction and has been chosen for this study as a representation of the quintessential US textbook. While Prentice Hall represents a ubiquitous curriculum, Singapore Math represents an uncommon alternative curriculum used in the U.S. These programs help represent the variety of curricula utilized in the U.S.

Singapore Math deserves to be looked at in comparison with the CCSSM because of Singapore's high international math ranking and its different approach to mathematics compared to traditional U.S. textbooks. Singapore's continual high achievements in mathematics has sparked the interest of the U.S. due to the concern of American failing schools and the worry of declining global competitiveness. Singapore's curriculum has been adopted in approximately 2500 U.S. schools and is popular with homeschoolers (D. Brillon, personal communication, April 9, 2013). It has gradually become well known throughout the U.S. as Singapore Math. Most U.S. textbooks attempt to cover a vast amount of information in a short amount of time; however, Singapore's curriculum devotes more time to fewer topics to ensure student comprehension.

Open source education provides resources that can be viewed by anyone online at no cost. These are a new source of mathematical programs that many regard as the way of the future. Open source education can provide teachers with additional options to help in the implementation of the CCSSM. In response to high textbook prices, CK-12, a non-profit organization established in 2007 by Neeru Khosla and Murugan Pal, produces free online resources for both students and teachers in a variety of subjects including mathematics. This program deserves to be analyzed because of its ease of accessibility and predicted future impact.

To conduct a comprehensive evaluation of the entire CCSSM is beyond the scope of this project. Therefore, I focused on one topic that is challenging for many students and will help to evaluate the mathematical rigor and coherency of the curricula stressed by the CCSSM: division of fractions. For students to fully understand division of fractions, they must rely on previous arithmetic concepts such as multiplication and repeated subtraction (Philipp, n.d.; Sharp \& 
Adams, 2002; Thompson, 1979; Wu, 2011; Yetkiner \& Capraro, 2009). Students must understand place value or how rational numbers are different and similar to whole numbers. Within various types of curricula, ones that refer to previously learned concepts are good indicators of its alignment with the CCSSM. Furthermore, division of fractions occurs frequently in algebra. Considering that algebra is the foundation for higher-level math courses, students' understanding of division of fractions is one concept necessary to ensure success in algebra and higher-level math courses.

\subsection{SPECIALIZED CONTENT KNOWLEDGE}

To better understand the complexity of teachers' knowledge, researchers have categorized teachers' knowledge into different domains: content knowledge, pedagogical knowledge, and curriculum knowledge (Ball, Thames, \& Phelps, 2008; Shulman, 1986). Specialized content knowledge is a form of knowledge used specifically for the teaching of mathematics. Specialized content knowledge guides teachers in determining patterns in a student's errors and ascertaining if nonstandard approaches to problems work. Specialized content knowledge requires elementary school teachers to understand elementary math at a conceptual level by emphasizing a comprehension of proofs and presenting mathematics to students in a variety of methods to enrich their understanding.

For example, when subtracting 168 from 307, some students might instead subtract 160 from 299, which yields the same answer-139. Why does this work? Furthermore, could it work in general? According to a teacher with specialized content knowledge, to avoid decomposing the three in the hundreds' place to subtract 168 from 307, a common number can be subtracted from these original numbers so that the larger number does not have to be regrouped. This will always result in the same answer. A teacher with specialized content knowledge would visually represent this with a number line, explaining that the distance between 168 and 307 as well as 160 and 299 is the same. In essence, both of the original values moved eight places to the left. Effective teachers must have specialized content knowledge to determine why alternative strategies work. Specialized content knowledge and the CCSSM require teachers to firmly understand mathematics; therefore each curriculum will be evaluated according to its support of teachers' specialized content knowledge.

\section{METHODOLOGY}

Three different evaluation tools were used to assess the curricula regarding their treatment of the "division of fraction" CCSSM. The Mathematical Tasks evaluation tool measures the cognitive demands of the curricula. The Six Essential Features Tool measures how comprehensive each curriculum is in addressesing the conceptual demands of the division of fractions standard. Lastly, the Curriculum Review Tool assesses how well the curricula support teachers' specialized content knowledge and how thorough each curriculum is in meeting the division of fraction standard. 


\subsection{THE COMMON CORE SIXTH GRADE DIVISION OF FRACTION STANDARD}

The CCSSM division of fraction standard states that students should:

Interpret and compute quotients of fractions, and solve word problems involving division of fractions by fractions, e.g., by using visual fraction models and equations to represent the problem. For example, create a story context for $(2 / 3) \div(3 / 4)$ and use a visual fraction model to show the quotient; use the relationship between multiplication and division to explain that $(2 / 3) \div(3 / 4)=8 / 9$ because $3 / 4$ of $8 / 9$ is $2 / 3$. (In general, $(a / b) \div(c / d)=a d / b c$. $)$

(National Governors, 2010, Grade 6 section Number System Standard 1, para. 1).

Most students are taught division of fractions using the invert and multiply method without conceptually understanding how to divide fractions (Siebert, 2002). Such students would not be able to reach the CCSSM described above, as it requires students to explain their answers. For all students to reach this CCSSM standard, teachers must understand commonly used algorithms and relationships to other mathematical topics. This directly demonstrates the need for specialized content knowledge to teach division of fractions (Ball, 1990; Tirosh, 2000; Yetkiner \& Capraro, 2009). For the duration of my project, I refer to this division of fraction CCSSM standard as simply "the standard."

\subsection{MATHEMATICAL TASKS}

Mary Kay Stein and Margaret Smith investigated the professional development of teachers. Their Mathematical Tasks (1998) are used to examine the conceptual demands of current programs in relation to the CCSSM. Stein and Smith (1998) have identified four different types of tasks that they have divided into lower and higher-level demands, shown in Table 1.

Table 1: Mathematical tasks

\begin{tabular}{l}
\hline Lower-Level Demands \\
\hline Memorization \\
Procedures without connections (plug and chug) \\
\hline Higher-Level Demands \\
\hline Procedures with connections \\
$\quad$ Doing Mathematics
\end{tabular}

Table from Stein \& Smith (1998)

"Doing mathematics" is the highest-level demand where students conceptually understand a topic. At this level, students can be given a problem in non-standard form and correctly solve and explain the answer. A problem is classified under "procedures with connections" when algorithms are used and the problem asks for some form of explanation. These Mathematical Tasks measure the cognitive demands of problems in the three curricula indicating their ability to meet the standard. 


\subsection{THE SIX ESSENTIAL FEATURES TOOL}

Research suggests that illustrating problems with pictures and representations, building off of students' existing knowledge, and creating real world problems are features that are the most helpful in teaching division of fractions conceptually (Philipp, n.d.; Sharp \& Adams, 2002; Thompson, 1979; Wu, 2011; Yetkiner \& Capraro, 2009). For example, since students are already familiar with repeated subtraction, multiplication, and equivalent fractions, these provide the building blocks and conceptual foundation to develop their understanding of division of fractions. The Six Essential Features Tool indicates the comprehensiveness in the programs' ability to address division of fractions. As the number of features incorporated into the curricula increases, the more comprehensive the curricula are at achieving a conceptual understanding of fractions. Table 2, below, creates a framework to evaluate the number of times each feature is referenced in each problem of the curricula. These features are not mutually exclusive as some problems may contain more than one feature.

Table 2: The Six Essential Features Tool [Sample Table]

\begin{tabular}{c|c}
\hline Features & Curriculum \\
\hline Repeated subtraction & $\mathbf{X}$ \\
\hline Equivalent fractions & $\mathbf{X}$ \\
\hline Multiplication & $\mathbf{X}$ \\
\hline Real World Problems & $\mathbf{X}$ \\
\hline Visual Representations & $\mathbf{X}$ \\
\hline Concepts set up first, procedures second & $\mathbf{X}$ \\
\hline Other & $\mathbf{X}$ \\
\hline
\end{tabular}

\subsection{THE CURRICULUM REVIEW TOOL}

Dr. Juliet Baxter, an associate professor in Education Studies at the University of Oregon, and Angie Ruzicka, a middle school science teacher in the Eugene 4J District, developed the Curriculum Review Tool. The Curriculum Review Tool was designed to help teachers assess mathematics curricula. It consists of yes or no questions regarding a curriculum's ability to: (a) develop mathematical ideas, (b) support effective instructional approaches, and (c) promote student thinking (Baxter \& Ruzicka, 2008). This tool is used to indicate how complete each program is in meeting the standard and how supportive the curricula are of teachers' specialized content knowledge. Additional questions accompany Dr. Baxter and Ruzicka's Curriculum Review Tool to more broadly evaluate the division of fraction standard. Examples of these questions include: Are there story problems? Are there equations that represent division of fractions? Does the curriculum include common misconceptions that students have with division of fractions and how teachers can explain it? These questions provide detailed information regarding the programs' ability to reach the standard and evaluate curriculum features that support teachers' specialized content knowledge. 
Using these three modes of analysis provides both quantitative and qualitative data pertaining to how well the curricula match the standard and if each curriculum is supportive of teachers' specialized content knowledge. Evaluating teacher manuals with Stein and Smith's Mathematical Tasks helps measure the cognitive demands of problems from current curricula. Because higher-level thinking parallels specialized content knowledge, the Mathematical Tasks also highlights the specialized content knowledge required of teachers using the curriculum. The Six Essential Features Tool illustrates how comprehensive each program is at explaining division of fractions, therefore assessing how well the program aligns with the standard. Baxter and Ruzicka's Curriculum Review Tool provides specific information pertaining to each program's strengths and weaknesses in achieving the standard as well as evaluating the curricula's support of teachers' specialized content knowledge.

\section{RESULTS}

As previously discussed, the three evaluation tools were used to measure different areas of the three curricula including: cognitive demands, comprehensiveness, and support of teacher's specialized content knowledge. The findings from these tools are discussed in the following subsections.

\subsection{MATHEMATICAL TASKS}

Using Stein and Smith's Mathematical Tasks, problems from each curriculum were categorized into one of four cognitive domains: memorization, procedures without connections, procedures with connections, or doing mathematics. Sixty-three of the 82 problems from Singapore Math promote higher-level thinking, which equates to procedures with connections and doing mathematics. This curriculum asked students to draw corresponding pictures with their work or solve word problems. This contrasts with CK-12 where only four of the 84 problems reached higher-level demands, none of which are classified under the highest level, "doing mathematics." Concerning Prentice Hall, 28 of the 98 problems reached higher cognitive demands, but like CK-12, the majority of their problems fell under "procedures without connections" which refers to the standard invert and multiply algorithm. Singapore Math, in contrast, did not contain problems where the curricula required memorized procedures or tasks. Graph 1 (below) illustrates a clear distinction between Singapore Math's high cognitive demands and CK-12 and Prentice Hall's reliance on lower-level thinking. Also notable is Prentice Hall's problems in all four categories. 


\section{Graph 1: Mathematical Tasks}

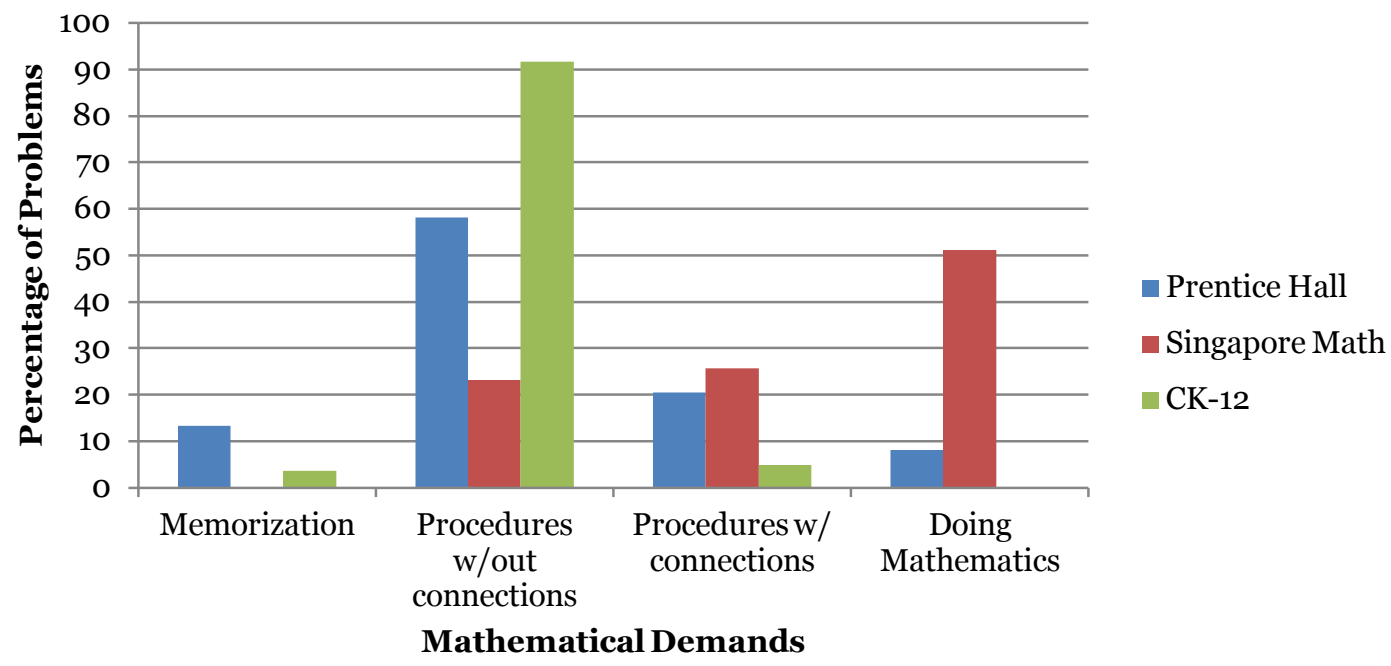

\subsection{THE SIX ESSENTIAL FEATURES TOOL}

The Six Essential Features Tool measures how comprehensive the curricula are in meeting the conceptual demands of the standard. Two features (repeated subtraction and equivalent fractions) were not found in the three curricula to help build students' conceptual understanding of fractions. The results are shown in the graph below:

\section{Graph 2: The Six Essential Features Tool}

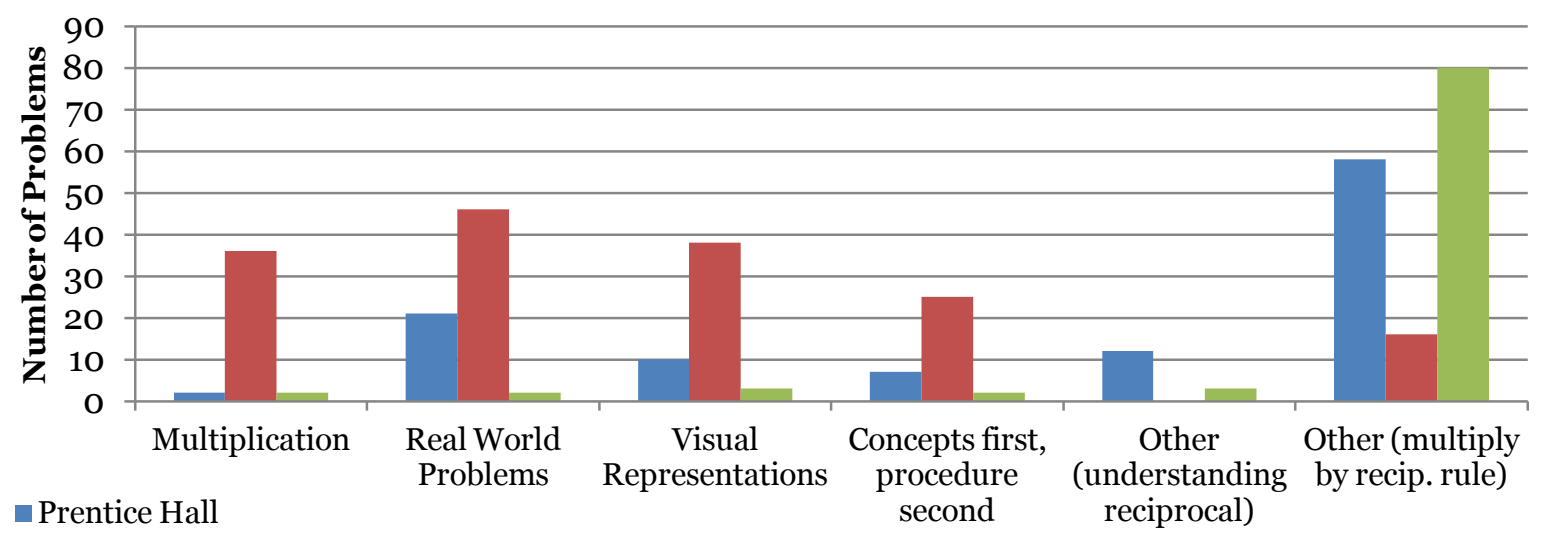

- Singapore Math

Note:

CK-12

None of the curricula contained problems with repeated subtraction or equivalent fractions

Thirty-eight problems from Singapore Math were presented with visual representations, whereas ten problems from Prentice Hall and three problems from CK-12 had visual 
representations. Furthermore, out of Singapore Math's 38 problems with visual representations, five of these asked students to use manipulatives, which provides further support for mathematical reasoning skills. Prentice Hall asked students to use manipulatives twice, but only one of the manipulatives was a part of the lesson plan. The other manipulative was offered as a side note to teachers.

Singapore Math outnumbered Prentice Hall and CK-12 in both categories of real world problems and multiplication. No problems from Singapore Math asked students to write the reciprocal of a fraction. Fifty-eight problems from Prentice Hall asked students to divide fractions using the multiply by reciprocal rule, whereas 80 problems from CK-12, and 16 problems from Singapore Math required this method. Not all of these features are mutually exclusive, and therefore overlap of problems did occur between these features during analysis. Singapore Math had the most overlapping features whereas CK-12 had the least.

\subsection{THE CURRICULUM REVIEW TOOL}

Baxter and Ruzicka's Curriculum Review Tool measured how comprehensively each curriculum meets the standard and how supportive the curricula are of teachers' specialized content knowledge. The individual curriculum elements have been analyzed for completeness and are shown in the graph below:

\section{Graph 3: The Curriculum Review Tool}

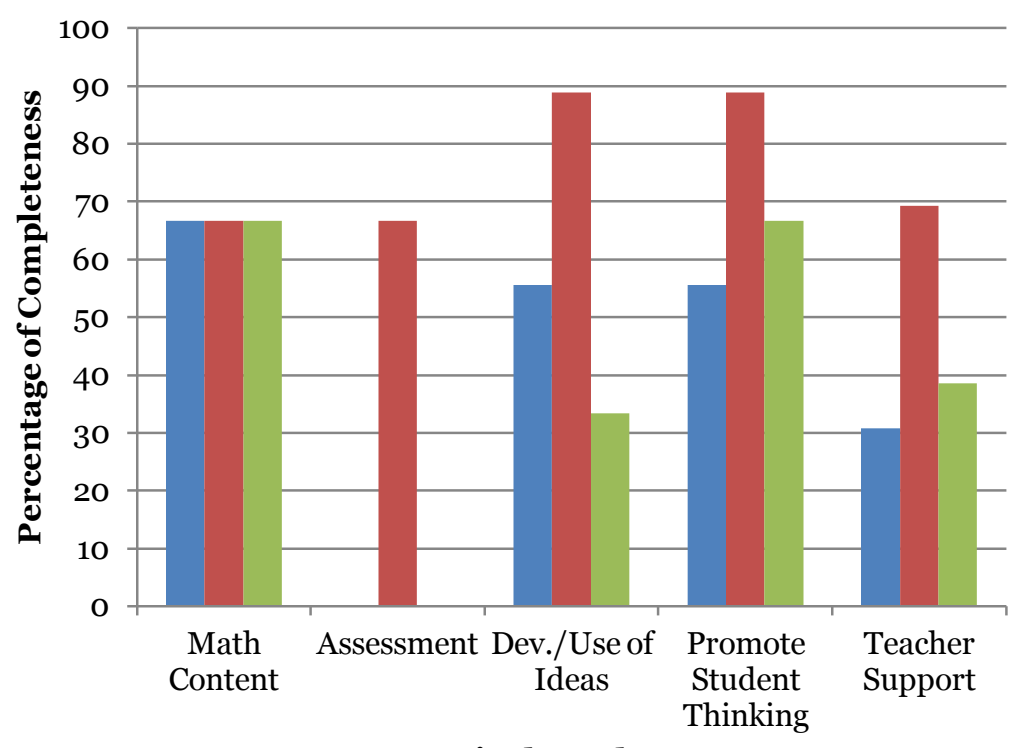

- Prentice Hall

- Singapore Math

CK-12

Curriculum Elements

Pertaining to math content, all three programs allow students to interpret and solve division problems, division story problems, and use visual fraction models to explain quotients. Although CK-12 qualifies in the story problem category, there were only two story problems presented, which were completed for the students. Singapore Math was the only curricula with a majority 
of problems that required students to make the connection between multiplication and division with fractions. CK-12 partially completed this category, but its main focus, as Prentice Hall's, was using the invert and multiply rule to solve division of fractions. None of the curricula had students use variables to find unknowns in division problems, and only Prentice Hall asked students to create their own story problem.

The assessment tasks for Prentice Hall and CK-12 provide a trivial way out for students to solve division of fraction problems by using the invert and multiple algorithm. Singapore Math does not heavily rely on this algorithm and therefore its application of ideas is closer to achieving the CCSSM. Out of the three curricula, only Singapore Math provides alternative solutions and advice for teachers to solve a particular division problem for students.

Concerning the development and use of mathematical ideas, Prentice Hall and CK-12 introduce the term "reciprocal" in preparation for teaching the invert and multiply rule. Singapore Math only refers to this word once. The majority of Prentice Hall's and CK-12's problems only ask students to solve division of fractions without a conceptual understanding. Furthermore, CK-12 does not contain word problems for students to solve independently. Although each curriculum does allow students to explain quotients via pictures, only three problems from Prentice Hall and two from CK-12 asked for this demonstration.

For the ability to promote student thinking about mathematics, Singapore Math references previously learned concepts when introducing division of fraction, reminding students of what it means to divide whole numbers. Prentice Hall does not reference any previously learned concept and CK-12 touches on the idea that multiplication is the inverse of division, but does not apply that relationship later to division of fractions. None of the curricula allow students to write about or reflect upon newly learned concepts.

The last domain of evaluation concerned the curricula's support of teachers and teachers' SCK. The three curricula support teachers' understanding of division of fractions, but Prentice Hall and CK-12 only accomplish this at a procedural level. Although each curriculum supports teachers to create a classroom environment that encourages students to make sense of mathematical ideas, CK-12 and Prentice Hall promote this using problems that require lower cognitive demands. None of the programs encourage teachers to promote student questioning during the lesson of division of fractions or address students' common misconceptions regarding division of fractions. None of the three curricula provide examples of students' work.

As Graph 1 and Graph 2 illustrate, there is a direct correlation between overlapping mathematical features and problems that require higher-level thinking. Simultaneously, Graph 1 and Graph 2 illustrate that a curriculum with a more equal distribution of the Six Essential Features correlates to higher-level thinking. This is associated with a more complete curriculum as seen by Graph 3 . 


\section{DISCUSSION}

The application of the evaluation tools on the collected data, suggest that a reliance on typically used algorithms hinders conceptual understanding of mathematics and teachers' SCK. This will make it more difficult to reach and implement the standard. The following subsections provide a more detailed analysis of the results of the study.

\subsection{MATHEMATICAL TASKS}

The results from Stein and Smith's evaluation tool indicate that Singapore Math is most closely matched to the standard because $76.8 \%$ of its problems reached higher-level demands. Only $28.6 \%$ of Prentice Hall's and $4.8 \%$ of CK-12's problems address higher-level demands. This clear distinction highlights that the implementation of the standard will be difficult for teachers relying on CK-12 and Prentice Hall, because these curricula involve primarily lower-level thinking. The CCSSM stresses conceptual thinking which CK-12 and Prentice Hall together do not even accomplish 50\% of the time according to Stein and Smith's evaluation tool. However, Prentice Hall's numbers in all four categories reflect a more versatile curriculum, as it demands both higher and lower-level mathematical thinking in comparison to Singapore Math and CK12. This versatility will appeal to different types of learners. However, the CCSSM is more concerned with higher-level thinking, and therefore, by examining Graph 1, it is clear how the cognitive demands of the standard are most closely reached by Singapore Math.

\subsection{THE SIX ESSENTIAL FEATURES TOOL}

The results from the Six Essential Features Tool show that the evaluated curricula did not refer to one third of the desired features. Researchers have deemed that these six features are essential to teach division of fractions conceptually (Philipp, n.d.; Sharp \& Adams, 2002; Thompson, 1979; Wu, 2011; Yetkiner \& Capraro, 2009). Without these features, the lesson plans for division of fractions are significantly less comprehensive. Therefore, it will be harder for teachers to make use of the CCSSM's framework for introducing equivalent fractions prior to division of fractions if teachers are using these curricula.

The features listed in Table 2 are not mutually exclusive; overlap between features occurred. Singapore Math had 79 overlapping features compared to Prentice Hall with 12 and CK-12 with eight. A typical problem from Singapore Math will demand more from a student because overlapping features require higher-level thinking. Therefore, Singapore Math coincides with the standard to a better extent then the other two curricula because conceptual understanding requires higher-level thinking.

Where Prentice Hall is more versatile by incorporating both higher and lower-level thinking, Singapore Math is more versatile because it incorporates a wider variety of problems. This allows Singapore Math to place greater conceptual demands on the learner. As Graph 2 presents, CK-12 and Prentice Hall make the majority of references to the traditional algorithm when presenting division of fractions. Prentice Hall suggests to teachers that, "Students might 
find it helpful to recite 'invert the second fraction and multiply' procedure softly as they work" (Charles, 2008). Relying this heavily on the multiply by reciprocal algorithm discourages conceptually thinking of mathematics and teachers' SCK due to the emphasis of the common algorithm. Singapore Math does not ask students to write reciprocals, indicating that the curriculum's emphasis is not teaching common algorithm.

Pertaining to the multiplication feature, Singapore Math encourages thinking of division in two different ways. For example, $(1 / 2) \div(1 / 4)$ is presented to teachers as, "How many $1 / 4$ 's are there in $1 / 2$ ?" or " $1 / 2$ is $1 / 4$ of what?" with corresponding pictures and explanations (Singapore Math, 2006, p.4). Prentice Hall and CK-12 do not provide different solving methods for a particular problem, which perpetuates the idea that there is only one correct way to solve mathematic problems. This will make it difficult to achieve the standard, as it requires students to understand fraction division problems in a multitude of ways.

Singapore Math encourages teachers to have students justify their answers to problems. These suggestions emphasize the importance of student thinking and processing rather than just obtaining the correct answer. This is quantitatively supported by the "concepts first, procedures second" feature. Both Prentice Hall and CK-12 provide numbered steps for students to follow the common algorithm, which does not support student thinking and processing of a problem. This presentation of division of fractions makes math monotonous and procedural, rather than logical and versatile. Problems that encourage conceptual understanding are not frequently embedded in CK-12 and Prentice Hall. For example, Prentice Hall's conceptual demands of division of fractions are most commonly found in small print to the side or at the bottom of pages.

From the Six Essential Features Tool, Prentice Hall's biggest strength is its inclusion of real world problems. However, Prentice Hall does not support teachers properly in helping students solve these problems. In contrast, Singapore Math encourages teachers to use visuals and diagrams to apply the concept of division of fractions to real world problems, whereas Prentice Hall spends $71.4 \%$ of its curriculum focusing on lower-level demands. Prentice Hall does not prepare students well to solve real world problems considering that most problems can be solved procedurally. This leaves teachers with little help to guide student thinking when approaching such problems. CK-12 only includes two real world problems that are already completed for students, whereas Prentice Hall at least provides students an opportunity to solve such problems. However, CK-12 has the technological advantage to make revisions easier and better meet this feature. For now, teachers using Singapore Math will have less difficulty implementing the standard.

\subsection{THE CURRICULUM REVIEW TOOL}

The results from the Curriculum Review Tool indicate the completeness of each curriculum to meet the standard and the curricula's ability to support teachers' SCK. Singapore Math, Prentice Hall, and CK-12 complete the standard's lower-level demands but miss the standard's requirements for higher-level demands. This will make it harder for teachers who use these 
curricula to implement the standard. For example, all three curricula have students interpret and solve division problems through some form of visual fraction models to understand problems, but the curricula's completeness diverge when discussing the relationship between division and multiplication as well as creating story problems. Where Prentice Hall provides opportunities for students to be creative by asking them to create their own story problem, Singapore Math and CK-12 succeed by relating division and multiplication. Prentice Hall and CK-12 succeed in introducing improper fractions while Singapore Math does not. In fact, the math content for each curriculum is not complete and this lack of completeness leads to less coherency and diminishes a student's conceptual understanding of division of fractions.

The Curriculum Review Tool further illustrates how the different structures of the curricula shape the development and use of mathematical ideas. For Prentice Hall and CK-12, problems introduced by the teacher were in the same style as problems to be completed independently by the student. This makes the common algorithm a necessity and diminishes the need for conceptual thinking. Although ten problems from Singapore Math were partially completed for students, hindering their independent thinking, 72 of the problems were not, which required students to conceptualize the problems independently. Therefore, division of fractions is better conceptually developed by Singapore Math than the other two curricula.

The three curricula do not provide students with the opportunity to write or reflect upon their understanding of division of fractions. This hinders the ability for each curriculum to promote students' thinking about mathematics. The inability of Prentice Hall and CK-12 to highlight the relationship between multiplication and division diminishes the opportunities for students to think about mathematics in familiar terms. This is confirmed by the results illustrated from Graph 2, which precisely indicates that Prentice Hall and CK-12 did not often refer to previously learned mathematical concepts.

The Curriculum Review Tool also highlights discrepancies between each curricula's ability to support teachers. Samples of students' work or responses are not provided to teachers in any of the evaluated curricula. This limits teachers' abilities to prepare for teaching division of fractions and does not support the development of their SCK. Singapore Math advises teachers to present "...division of fractions through the use of diagrams so that they [students] can apply principles to word problems, rather than simply memorizing "invert and multiply" (2006, p. 5). The Singapore Math curriculum is able to better support teachers than Prentice Hall and CK-12 due to its greater emphasis on conceptual thinking.

From the teachers' support domain, CK-12 and Prentice Hall do not encourage teaching division of fractions from a conceptual point unlike Singapore Math. This perpetuates the view of mathematics as a set of rules to follow rather than a logically solvable subject. This will make it more difficult for the two curricula to achieve the standard. 


\subsection{LIMITATIONS}

Although the three evaluation tools help elucidate where current curricula stand in comparison to the CCSSM, limitations with this study exist. This study has examined the treatment of only one mathematical concept in each curriculum. Examining one mathematical concept is surely not a comprehensive evaluation of the CCSSM as a whole. The results from the evaluation tools provide one snapshot to answer the questions of how well current curricula match the CCSSM and how well current curricula aid teachers' implementation of the new standards. Curricula alone cannot fully answer this question. Teachers' pedagogical practices, students themselves, and how problems are solved by students are all variables which contribute to answering the research questions: how well do current curricula match the CCSSM, specifically regarding division of fractions, and how supportive is curricula of teachers' SCK? Furthermore, other materials besides curricula, such as supplemental worksheets, can be used by teachers and studentswhich were not evaluated in this study. Case studies about teachers' knowledge and use of the curricula are needed. Case studies are needed to determine how students solve division of fractions when exposed to these curricula. Such analyses would provide more comprehensive results.

Limitations arise within the Six Essential Features Tool, which provide six features that are not mutually exclusive. Some problems were counted in two or more categories due to overlapping features. This hinders the ability to interpret the calculated values as percentages and inhibits a comprehensive comparison of the three curricula. This might affect the validity of the findings, because one problem that may have contained the feature of multiplying by the reciprocal, discouraged by the CCSSM, might have also contained the visual representation feature, encouraged by the CCSSM. Although overlapping features help illustrate the level of intensity for each problem, the intensity can vary depending on the number of features overlapped, leading to ambiguity.

A future study could quantify students' conceptual understanding of division of fractions when exposed to only certain features as listed in Table 2. This would provide information as to which features are most important in the conceptually understanding of division of fractions. Assuming that each feature is equally valued, these programs are one third incomplete to conceptually teach division of fractions.

Concerning the Curriculum Review Tool, 40 equally weighted categories were assessed and evaluated by percentages. The category assessing the curricula's ability to welcome student curiosity might be weighted less than the categories assessing the curricula's ability to match the standard. For this project, the categories were allocated the same percentage points. Further research investigating the importance of each category would make the results more helpful.

To decide if the CCSSM are the optimal standards to teach to is beyond the scope of this project. However, standards like the CCSSM, which emphasize clarity, focus, coherency and rigor can only help students' mathematical thinking and help solve the math challenge. The 
CCSSM may or may not be the "best" standard (which further research should investigate), but because it has been so widely adopted; it is the natural point for comparing curricula.

\section{CONCLUSION}

As this study shows, Singapore Math is more closely matched to the standard than Prentice Hall, and Prentice Hall more closely aligns with the standard than CK-12. From the analysis, my prediction holds true that Singapore Math more closely meets the standard. However, this is not a case of "winners" and "losers." Each curriculum has important qualities, which support the implementation of the standard and should be incorporated in new resource tools to teach division of fractions conceptually. This includes Singapore Math's conceptual emphasis of mathematics by incorporating multiple mathematical features in its problems, Prentice Halls' inclusion of real world problems which encourages higher-level thinking, and CK-12's ease of making revisions to reach the standard. However, CK-12's and Prentice Hall's overreliance on the invert and multiply algorithm is problematic, as it diminishes students' conceptual understanding and teachers' SCK for division of fractions.

Guidelines that encourage teachers to bypass conceptual understanding for quick, memorized rules can have devastating effects. These guidelines encourage teachers to think of mathematics as a set of procedures rather than a coherent, logical, and understandable subject. Curricula, which emphasize procedural thinking, have greater potential to diminish teachers' SCK. Therefore, students may not be provided with the knowledge needed for a firm understanding of mathematics and will have difficulty reaching the objectives of the CCSSM. To meet the standard, and the CCSSM as a whole, curricula must incorporate problems that scaffold students' thinking and allow them to solve higher-level tasks. The curricula must also support teachers' SCK so that students can reach their optimal learning capacities.

The objectives of the CCSSM will improve U.S. mathematic education and help solve the U.S. challenge in mathematics. If all U.S. schools adopt the CCSSM and teach to these standards, students will develop better critical thinking skills, and understand the importance of asking questions, such as exploring why algorithms work. Furthermore, they would understand the coherency of mathematics. Equally important, such cognitive processes that the CCSSM stresses is applicable to other fields of study such as science and history. Students will not just accept presented facts, but question and investigate them. In doing so, the CCSS helps students become actively engaged with the material making their education more meaningful, pertinent, and exploratory.

Curricula, which fail to meet the standard and support procedural methods, only perpetuate the belief that mathematics is simply a subject of random rules. The beauty of arriving at an answer in multiple ways, the coherency of the subject, and the reward of persevering becomes fogged. Mathematics, as well as other subjects, becomes bland and meaningless when standards and curricula only require students to memorize facts and procedures. 
Determining the quality of mathematics education cannot solely rely on standards themselves. Teachers' SCK, curricula, and funding of schools are few of many variables that can affect the quality of mathematics. However, the CCSSM are a step in the right direction regarding the U.S. math challenge. If the standards are met, they will help solve the math challenge because they require students and teachers to draw connections between already understood concepts. Overall, this reinforces their previous mathematical knowledge and problem solving skills.

Similarly, other areas of new development must be implemented to help solve the math challenge and ensure students' conceptualization of the standard. This includes assessment and teacher development programs. Assessments play a significant role in what is taught in the classroom. Therefore, problems on assessments must ask higher-level questions and not provide a trivial way out for students to solve the problem. Adherence to the standard through curricula and assessments cannot solve the math challenge alone. Teachers' knowledge of mathematics must be proficient to ensure students are taught mathematics clearly and logically. Teacher development and training programs must exist early on, where prospective teachers begin thinking of pedagogical practices of mathematics. Such collaboration must then continue as they begin teaching, whereby together teachers create mathematical lessons and discuss teaching strategies to use in the classroom.

Adopting and teaching to the standard is necessary to provide the foundation for students' success in algebra and other higher-level math courses. Higher-level thinking curricula will help ensure this foundation is laid properly. The CCSSM will help reconstruct mathematics education and solve the math challenge because the objectives develop students' problem solving skills, rather than encouraging the use of procedures and algorithms. Repetitive and procedural methods inhibit the ability to solve harder problems. Additionally, the cognitive thought processes that the CCSSM stresses help change the perception that education is bland. The discourse of education should not debate whether or not new objectives or standards should be implemented. The discourse should concern how educators can aid their students in reaching higher-levels of thinking. After all, student learning is the greatest goal for educators. In the words of John Dewey, a major leader of progressive education: If only all instructors realized "that the quality of mental process, not the production of correct answers, is the measure of educative growth."

\section{ACKNOWLEDGEMENTS}

I would like to thank my advisor, Dr. Juliet Baxter, for her constant guidance, valuable time, and expertise that has propelled my study forward. I would also like to thank Brenton MacDonald, George Carollo, and Chelsea Arsenault for their dedication and effort to help finalize this project. 


\section{REFERENCES}

Ball, D. L. (1990). The Mathematical Understandings That Prospective Teachers Bring to Teacher Education. Elementary School Journal, 9o(4), 449-466.

Ball, D. L., Thames, M. H., \& Phelps, G. (2008). Content Knowledge for Teaching: What Makes it Special? Journal of Teacher Education, 59, 389-407.

Baxter, J., \& Ruzicka, A. (2008). Curriculum Review Tool.

Charles, R.I. (2008). Prentice Hall Mathematics: Course 1. Upper Saddle River, NJ: Pearson Prentice Hall.

Coleman, J. (1966). Equality of educational opportunity: Executive summary. Washington, DC: Department of Health, Education, and Welfare.

Gardner, D.P., Larsen, Y.W., Baker, W.O., Campbell, A., Crosby, E. A., Foster, C. A., Wallace, R. (1983). A Nation at Risk: The Imperative for Educational Reform. Washington, D.C.: U.S. Department of Education.

Ginsburg, A., Leinwand, S., Anstrom, T., Pollock, E. (2005). What the Unites States Can Learn From Singapore's World-Class Mathematics System (and what Singapore can learn from the United States): An Exploratory Study. Washington, DC: American Institutes for Research.

Greenberg, D., \& Kershaw, J. (2012a, October). Dividing Fractions. In CK-12 Middle School Math Multiplication and Division of Fractions (Chapter 7.4). Retrieved from http://www.ck12.org/user\%3AbGVhbm5hYzVAeWFob28uY29t/book/7.4-Dividingfractions/r1/section/1.0/Dividing-Fractions/

Greenberg, D., \& Kershaw, J. (2012b, October). Dividing Mixed Numbers. In CK-12 Middle School Math Multiplication and Division of Fractions (Chapter 7.5). Retrieved from http://www.ck12.org/user\%3AbGVhbm5hYzVAeWFob28uY29t/book/7.5-Dividing- mixednumbers/r1/section/1.0/Dividing-Mixed-Numbers/

Grossman, P., \& Thompson C. (2008). Learning from curriculum materials: Scaffolds for new teachers? Teaching and Teacher Education, 24, 2015-2026.

Hill, H. C., Rowan, B., \& Ball, D. L. (2005). Effects of teachers' mathematical knowledge for teaching on student achievement. American Education Research Journal, 42, 371-406.

Klein, J.I., Rice, C., Levy, J. (2012). U.S. Education Reform and National Security. Council on Foreign Relations. Independent Task Force Report No. 68.

Ma, L. (1999). Knowing and Teaching Elementary Mathematics: Teachers' Understanding of Fundamental Mathematics in China and the United States. New York: Routledge.

National Center for Education Statistics. (2011a). Trends in International Mathematics and Science Study. Retrieved from http://nces.ed.gov/timss/

National Center for Education Statistics. (2011b). Program for International Student Assessment. Retrieved from http://nces.ed.gov/surveys/pisa/index.asp

National Governors Association Center for Best Practices, Council of Chief State School Officers. (2010). The Common Core State Standards for Mathematics. Washington D.C.: National Governors Association Center for Best Practices, Council of Chief State School Officers. 
Philipp, R. (n.d.). Unpacking A Conceptual Lesson: The Case of Dividing Fractions. Retrieved from http://www.sci.sdsu.edu/CRMSE/IMAP/pubs/Unpacking.pdf

Sharp, J., \& Adams, B. (2002). Children's constructions of knowledge for fraction division after solving realistic problems. The Journal of Educational Research, 95, 333-347.

Shulman, L. S. (1986). Those who understand: Knowledge growth in teaching. Educational Researcher, 15(2), 4-14.

Siebert, D. (2002). Connecting informal thinking and algorithms: The case of division of fractions. In B. Litwiller \& G. Bright (Eds.), Making sense of fractions, ratios, and proportions: 2002 yearbook (pp. 247-256). Reston, VA: National Council of Teachers of Mathematics.

Singapore Math. (2003). Primary Mathematics 6B Textbook (U.S. ed.). Singapore: Marshall Cavendish Education.

Singapore Math. (2006). Singapore Primary Mathematics: Teacher's Guide 6B For U.S. Edition ( $3^{\text {rd }}$ ed.). Oregon City, OR: SingaporeMath.com Inc.

Stein, M., \& Smith, M. (1998). Mathematical Tasks as a Framework for Reflection: From Research to Practice. Mathematics Teaching in the Middle School, 3(4), 268-275.

Thompson, C. (1979). Teaching Division of Fractions with Understanding. Arithmetic Teacher $27,24-27$.

Tirosh, D. (2000). Enhancing prospective teachers' knowledge of children's conceptions: The case of division of fractions. Journal for Research in Mathematics Education, 31, 5-25.

Wu, H. (2011). Teaching Fractions According to the Common Core Standards. American Mathematical Society. 1-88. Retrieved from http://math.berkeley.edu/ wu/CCSSFractions.pdf

Yetkinr, Z. E., \& Capraro, M. M. (2009). Research summary: Teaching fractions in middle grades mathematics. Retrieved from http://www.amle.org/Research/ResearchSummaries/TeachingFractions/tabid/1866/De fault.aspx 